The Eurasia Proceedings of Educational \& Social Sciences (EPESS), 2015

Volume 2, Pages 123-131

ICEMST 2015: International Conference on Education in Mathematics, Science \& Technology

\title{
A SURVEY OF STUDENTS PARTICIPATING IN A COMPUTER- ASSISTED EDUCATION PROGRAMME
}

\author{
Elif BİNBOĞA YEL \\ Eastern Mediterranean University \\ Orhan KORHAN \\ Eastern Mediterranean University
}

\begin{abstract}
This paper mainly examines anthropometric data, data regarding the habits, experiences and attitudes of the students about their tablet/laptop/desktop computer use, in addition to self-reported musculoskeletal discomfort levels and frequencies of students participating in a tablet-assisted interactive education programme. A two-part questionnaire was used to collect data. Results revealed that students are experiencing musculoskeletal discomforts highly at the neck, lower back and upper back regions.. The survey results are of critical importance because making reasonable recommendations to the new generations for healthy use of desktop/laptop/tablet computers is only possible if we can understand the relationships and risk factors involved in and eliminate the risks to prevent musculoskeletal discomfort.
\end{abstract}

Key words: Tablet, laptop, desktop, musculoskeletal discomfort.

\section{INTRODUCTION}

Getting acquainted to technologies such as laptop or tablet computers at very early ages can be good with the perspective of training employees with skills to meet on-going demand of technologically skilled workforce of today's world. Besides, such modern portable technologies are playing an ever-increasing role in the lives of children with the widespread availability and usefulness of the the Internet. However, given the fact that musculoskeletal development of children and adolescents is still on going, potential musculoskeletal problems resulting from usage of such technologies must not be disregarded.

There are some studies in the literature reporting that there exists prevalence of musculoskeletal discomfort in children and/or adolescents using portable technologies like laptops and tablets [Straker et al. (1997), Harris and Straker (2000), Greig et al. (2005), Sommerich et al. (2007), Straker et al. (2008)]. However, to the best of our knowledge none of the existing studies focusing on laptop or tablet computer use of children (and/or adolescents) involved children (and/or adolescents) from all grades of middle school and high school $\left(6^{\text {th }}, 7^{\text {th }}, 8^{\text {th }}\right.$, $9^{\text {th }}, 10^{\text {th }}, 11^{\text {th }}$ and $12^{\text {th }}$ graders $)$. This paper tries to fill this gap by studying experienced musculoskeletal discomfort by the students of a combined middle and high school in northern Cyprus $\left(6^{\text {th }}, 7^{\text {th }}, 8^{\text {th }}, 9^{\text {th }}, 10^{\text {th }}, 11^{\text {th }}\right.$ and $12^{\text {th }}$ grades), which is running a computer-assisted interactive education programme.

186 students participated in a two-part questionnaire for obtaining general information on children's habits related to desktop/laptop/tablet computer use, relationship between demographics of the subjects and the frequency of musculoskeletal discomfort they experience, relationship between their daily use of such technologies and musculoskeletal discomfort they experience in their upper limb body parts, as well as study the correlation between musculoskeletal discomfort and their laptop, desktop, and tablet use.

\section{METHODS}

\section{Data Collection}

In order to achieve genralizability, students from different state and private high schools were aimed as potential participants. Thus, students with varying demographic structure and soci-cultural background were guaranteed to participate in this research.

- This is an Open Access article distributed under the terms of the Creative Commons Attribution-Noncommercial 4.0 Unported License, permitting all non-commercial use, distribution, and reproduction in any medium, provided the original work is properly cited.

- Selection and peer-review under responsibility of the Organizing Committee of the conference

*Corresponding author: Elif BİNBOĞA YEL- icemstoffice@ gmail.com 
At the time of the study, certain state and private schools have adapotedcomputer-assisted interactive education in some particular lectures in northern Cyprus. A total of 200 questionnaires were distributed to all classes in the schools. At the end, a total of 186 students consented to participate in the survey of the study. Thus, a total of 186 questionnaire forms were completed and collected back. In other words, we had a response rate of $93 \%$ from those whose parents gave written consent to participate in the study.

\section{Study Design and the Questionnaire}

The study design involved a cross-sectional survey of children using computer for educational purposes and data was collected during in January-April 2015.

The questionnaire was composed of two parts; first part of the utilized questionnaire tool is derived from the Dutch Musculoskeletal Questionnaire (DMQ), which was originally developed by Hildebrandt et al. (2001). The standard DMQ have been modified and shortened in order to fit the needs of the study. This section of the questionnaire part sought information on background variables (like age, height, weight, gender), on reasons, location, duration and history of desktop/laptop/tablet computer use of the participants, and on emotional background of the participants while using a desktop/laptop/tablet computer, and on lifestyle of the participants (sports activities, smartphone usage etc.).

A way for determining prevalence of musculoskeletal complaints is through the use of symptom surveys (Hedge et al. 1999). The second part is composed of SS-CMDQ, which is an adaptation of CMDQ (a symptom survey). SS-CMDQ, which includes a body map diagram to track the locations of musculoskeletal discomfort, was administered to study the correlation between musculoskeletal discomfort and tablet computer use. It should be noted that most of the students uses their tablets with desk stands in accordance with the school's policies.

The resulting two-stage questionnaire tries to obtain a representation of the relationships between the desktop/laptop/tablet use and musculoskeletal symptoms among students using tablet computers in classrooms. In general, the questionnaire included a combination of measures for evaluating musculoskeletal outcomes related to children's desktop/laptop/tablet exposure for educational purposes.

\section{Development of the Questionnaire Questions}

First four questions of the first part of the questionnaire, which are asking age, gender, height and weight of the participants, aim to collect demographic data in order to be able to describe the study population. This descriptive demographic data helps to identify range of ages, weight, height etc. of our sample population. These questions is also useful in comparing demographics related changes in reported musculoskeletal symptoms. The fifth question of the first part inquired about the type of computer preferred by the students (desktop/laptop/tablet computer). This is to determine whether there is a difference in the frequency and level of musculoskeletal discomfort experienced between the students who are exposed to one of these technologies and the students who are exposed to all or more than one of these technologies. Or to find an answer to the question "does any of the three types of computer used increase the frequency of level of discomfort experienced?" Question 6, which asks about the activities that the subjects are using the computers (all three types) for and the corresponding durations of use, is designed to check whether engaging in a specific activity and/or using the mentioned types of computers for that specific activity for long periods of time results in an increased amount of reported discomfort or pain? Question 6 helps us to determine the average duration of computing time for students in different grades on a typical school day. The questions related to the setting (home, school etc.) of computer (three computer types - desktop, laptop and tablet computers) use or duration of span of computer use are asked to determine whether the mostly preferred setting or duration of span of computer use related to the amount and/or area of pain. Questions from 9 to 11 check whether the experienced feelings of subjects regarding desktop/laptop/tablet computers correlates with the frequency of discomfort experienced in any body region. Question 12 is designed to ascertain if students engaging in certain artistic or physical activities report less discomfort compared to other students. Question 13 is to identify whether the students experienced accidents or had injuries in the past one year. The students with "Yes" answers to this question shall be removed from investigations regarding reported pain to avoid involving the effects of an accident in evaluation of computer use related pain. The last question of the first part of the questionnaire checks if the durations of smart phone use correlates with the frequency of amount of musculoskeletal discomfort.

Second part of the questionnaire (SS-CMDQ) is a one-page addition to the first part, which addresses the frequency (in the past week) and level of musculoskeletal discomfort and pain as well as the effect of experienced musculoskeletal discomfort to the performance of academic activities. In order to help selfadministration of the questionnaire by reporting musculoskeletal complaints with respect to the corresponding body regions, this part of the questionnaire involves a body map to assist with identification of body regions and quantification of discomfort.

The SS-CMDQ asks sixty questions about the frequency of musculoskeletal discomfort/pain in 20 body parts referring to the previous week. The frequency of discomfort is assessed on a scale from 0 (none) to 4 (several times a day) and level of discomfort from is assessed on a scale ranging from 1 (slightly uncomfortable) to 3 (very uncomfortable). 


\section{Survey Administration}

The two-part questionnaire was administered in approximately 20-25 minutes in all classrooms. The participants were provided with both Turkish and English version of the two-stage questionnaire. The first part, which has been developed in this study using the DMQ, was translated into Turkish. Both Turkish and English versions of the SS-CMDQ part have already been developed by Erdinç and Ekşioğlu [CUergo (1999)].

The SS-CMDQ part of the survey process is also analysed for determining the possible postural problems of the participants. Discriminant Analysis was applied to determine whether a set of variables is effective in predicting category membership, and to identify statistically significant factor(s) which contribute(s) formation of the musculoskeletal discomfort due to laptop, dekstop, and tablet use.

\section{RESULTS AND FINDINGS}

\section{Descriptive Statistics}

The results of the questionnaire revealed that $47.3 \%$ of the respondents were male students, and $52.7 \%$ were female students. Table 1 illustrates the demographic structure of the students.

Table 1. Student Demographics $(n=186)$

\begin{tabular}{cccc}
\hline Variables & Range & Mean & Std. Dev. \\
\hline Age & $11-20$ & 14.64 & 2.505 \\
Height & $1.37-1.87 \mathrm{~m}$ & 1.63 & 0.116 \\
Weight & $30-96 \mathrm{~kg}$ & $56.31 \mathrm{~kg}$ & 14.995 \\
\hline
\end{tabular}

Majority of the students (a total of 70.1\%) stated that they were using either a combination of tablet, laptop, and desktop computers, or all of them in their daily life. Only $29.8 \%$ of the students provided that they were using only one of tablet, laptop, and desktop computer (table 2)

\begin{tabular}{ccc} 
Table 2. Tablet / Laptop / Desktop Use Habits $(\boldsymbol{n = 1 8 6}$, hops= 2) \\
\hline Only tablet & $4,3 \%$ & 8 \\
Only laptop & $17,9 \%$ & 33 \\
Only desktop & $7,6 \%$ & 14 \\
Desktop \& laptop & $14,1 \%$ & 26 \\
Laptop \& tablet & $18,5 \%$ & 34 \\
Desktop \& tablet & $12,5 \%$ & 23 \\
All & $25,0 \%$ & 46 \\
\hline
\end{tabular}

Figure 1 shows "communication" is not a preferred reason of use laptop, desktop, and tablet computers among students. Majorities of those who use any of laptop, desktop, and tablet for communication purpose, use these computers for less than 1 hour.

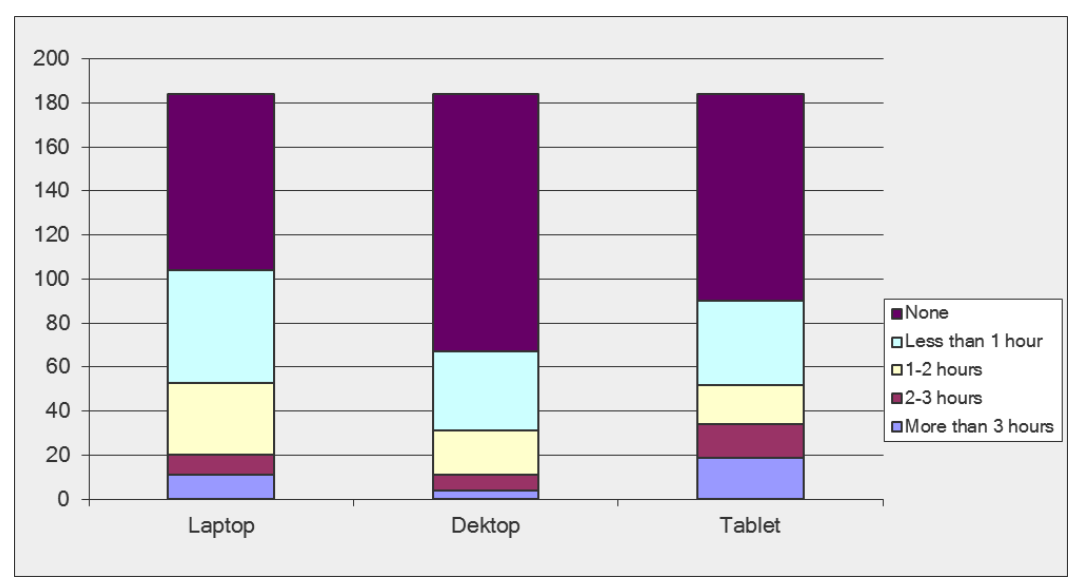

Figure 1. Use Of Laptop, Desktop, And Tablet For Communication Purpose $(n=186$, hops= 2)

Unexpectedly, a very high majority of the students provided that they were not using any of laptop, desktop, and tablet computers for playing games. When they play games, students prefer laptop, tablet, and desktop computers respectively (figure 2). 


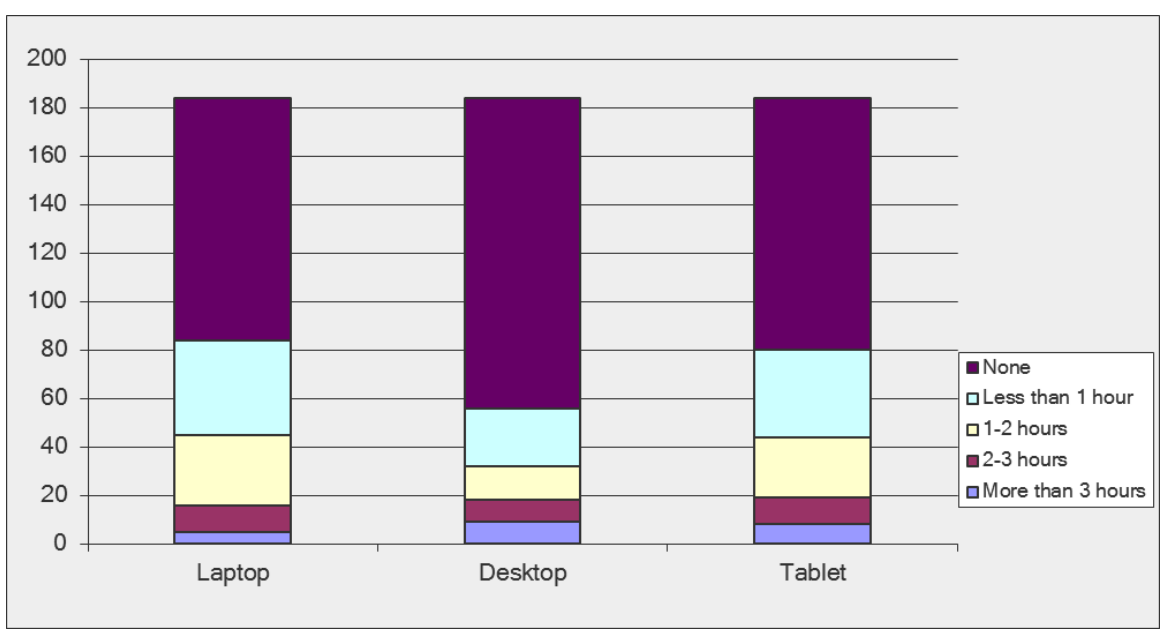

Figure 2. Use Of Laptop, Desktop, And Tablet For Playing Games $(n=186$, hops= 2)

Expect laptop users, majority of the students stated that they do not use desktop and tablet to watch films. However, more than half of the participants provided that they used laptop to watch films (figure 3).

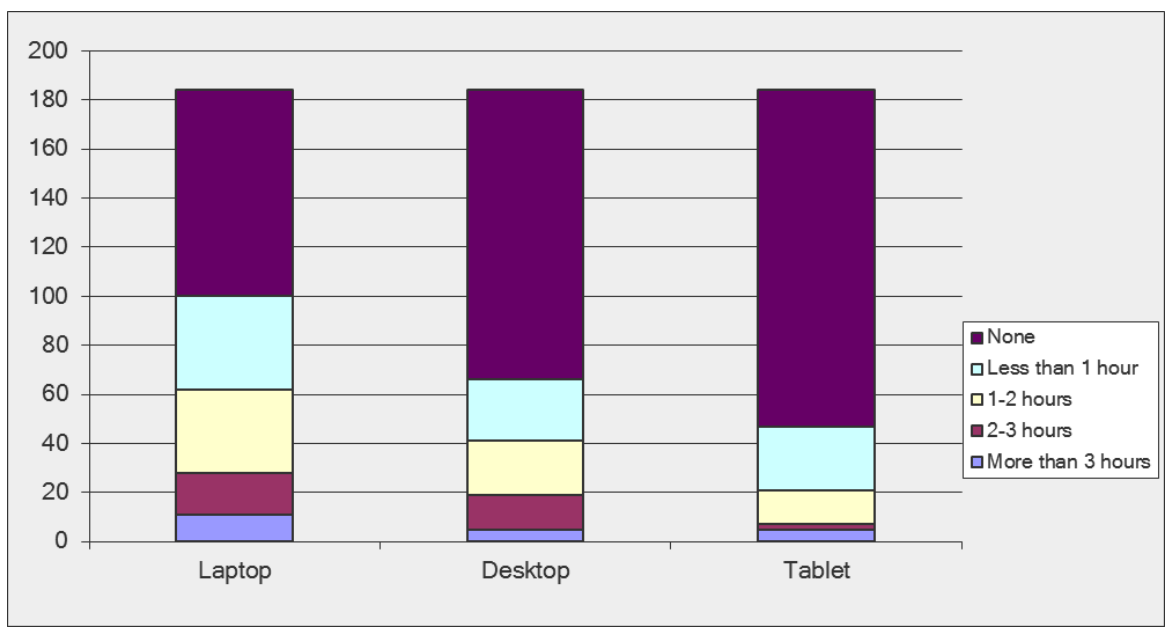

Figure 3. Use Of Laptop, Desktop, And Tablet To Watch Films ( $n=186$, hops= 2)

A very high majority of the students provided that they do not use any of laptop, desktop, or tablet computers for studying outside the school. Tablets, particularly, were observed to be least preferred computers for studying purposes outside the school. On the other hand, when they study, students provided that they prefer laptop computer (figure 4).

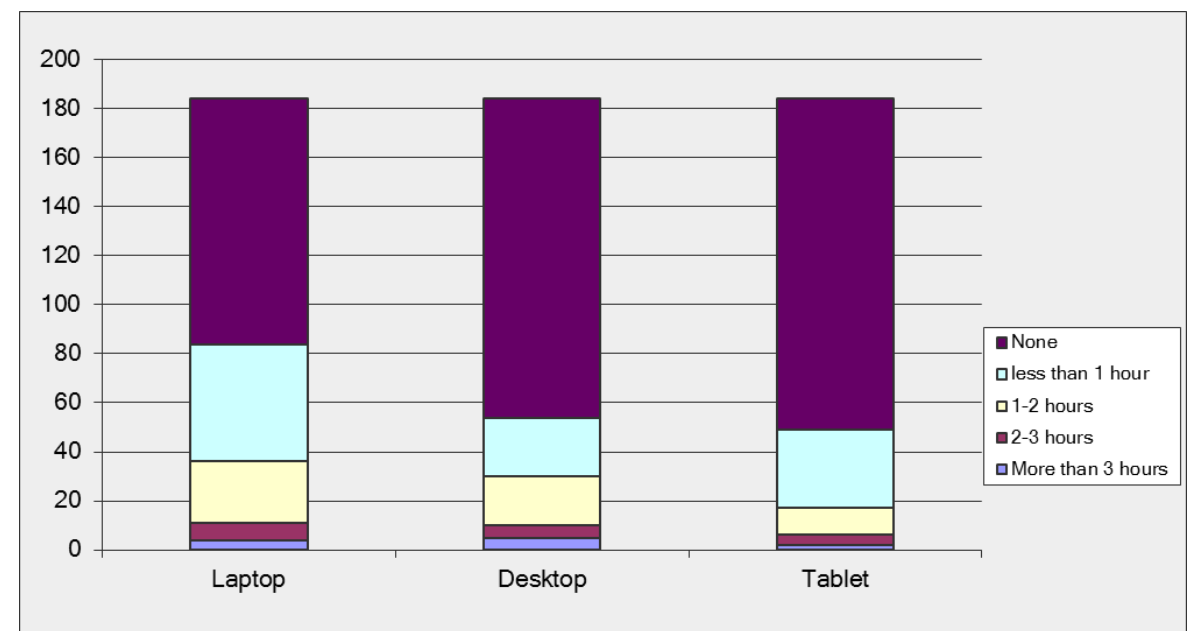

Figure 4. Use Of Laptop, Desktop, And Tablet To Study Outside The school $(n=186$, hops= 2$)$

Tablets were observed to be the least used computer at schools, whereas almost one third of the students stated that they use laptops during the lecture (figure 5). 


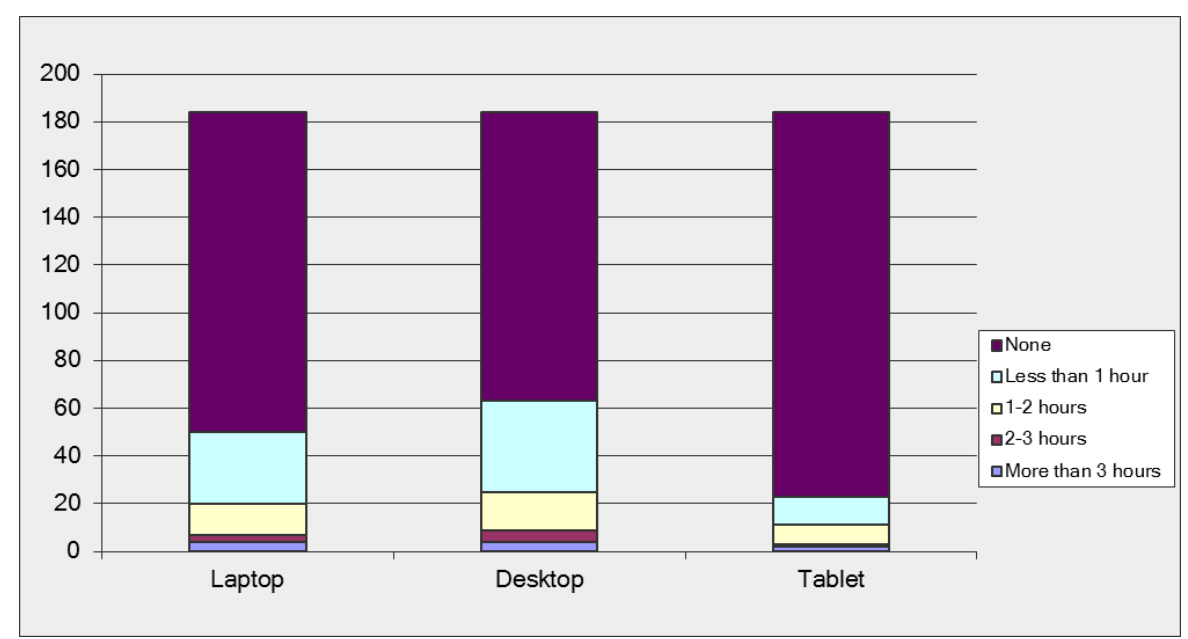

Figure 5. Use Of Laptop, Desktop, And Tablet During Lectures At School $(n=186$, hops= 2)

Laptops were stated to be the most preferred computer for internet surfing by the students, whereas desktops were not popular among students for the same purpose. However, tablets were observed to challenge the laptops for internet surfing. During tablet use, the number of internet surfers for less than 1 hour and 1-2 hours were also observed to be very close (figure 6).

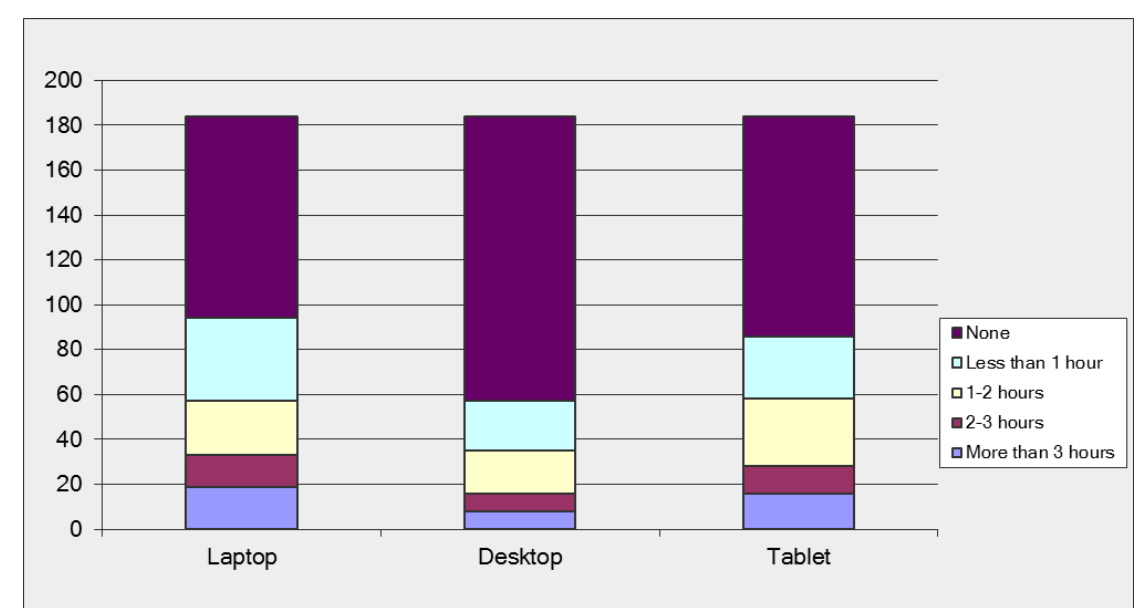

Figure 6. Use Of Laptop, Desktop, And Tablet For Internet Surfing $(n=186$, hops= 2)

Figure 7 illustrates that the majority of the students do not use any of laptop, desktop, and tablet for reading newspaper, book, magazines, etc... Those who use laptop, desktop, and tablet for reading were observed to spend less than 1 hour per day.

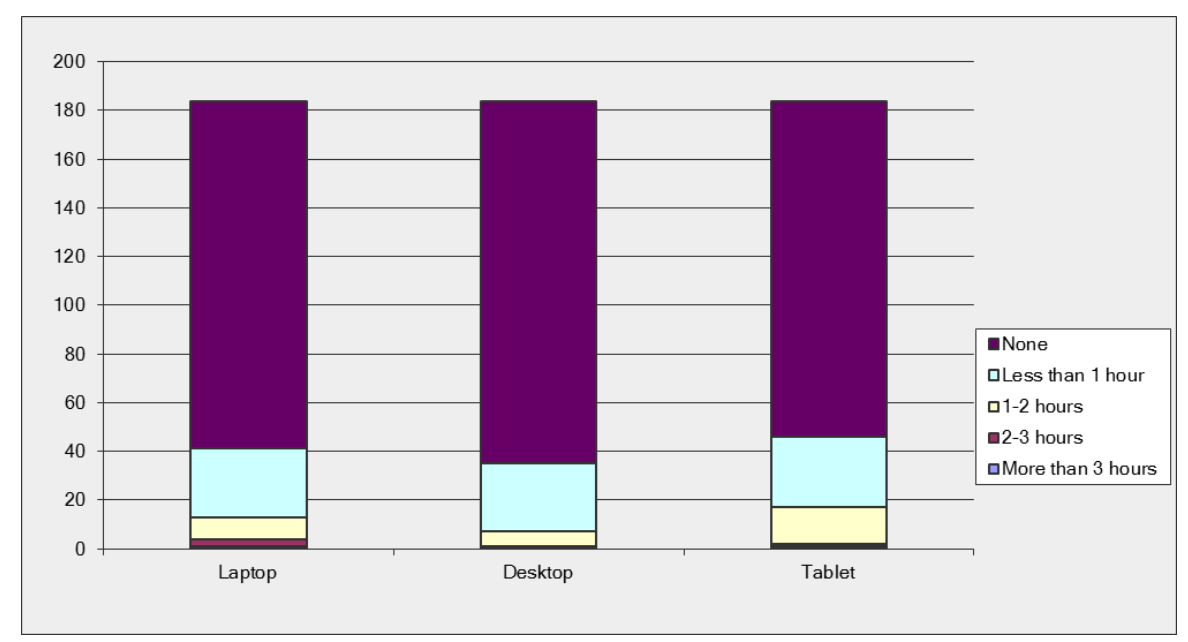

Figure 7. Use Of Laptop, Desktop, And Tablet For Reading ( $n=186$, hops= 2) 
Most of the students provided that they do not use laptop, desktop, and tablet computers to write dairies, blogs, and posts on to the internet. Among those who write dairies, blogs, and posts, laptops were observed to be the most preferred computer type.

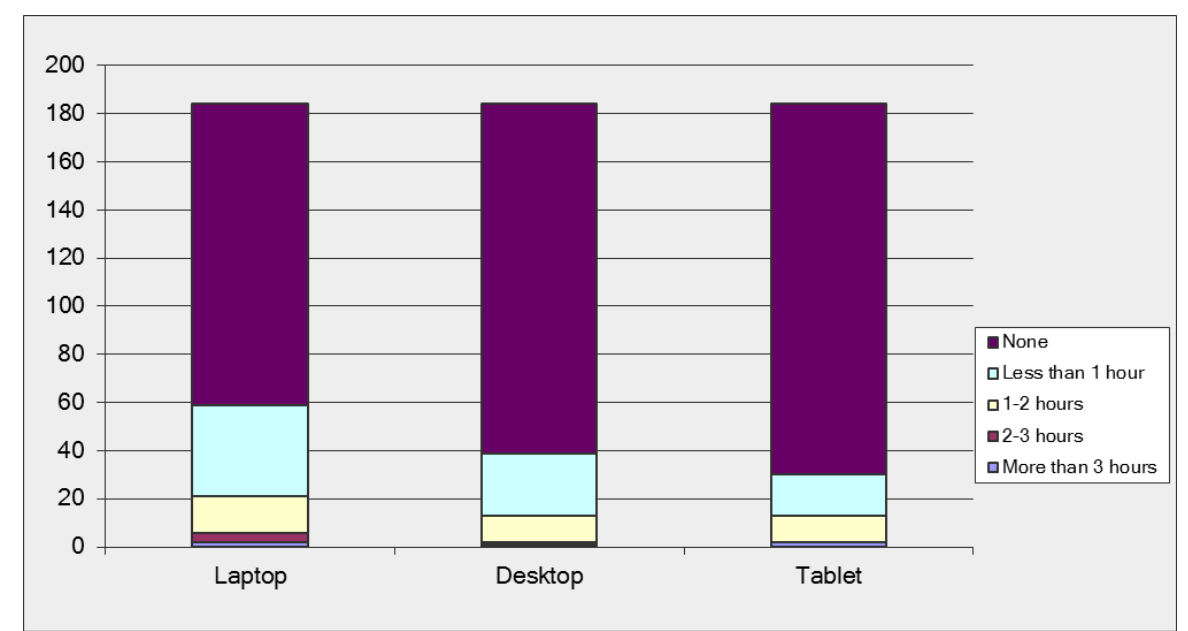

Figure 8. Use Of Laptop, Desktop, And Tablet For Writing Blogs, Posts, Dairies $(n=186$, hops= 2)

Table 3. Place Of Computer Use Mostly $(n=186)$

\begin{tabular}{llll}
\hline Place of use & Desktop & Laptop & Tablet \\
\hline None & $34,8 \%$ & $21,2 \%$ & $37.0 \%$ \\
At home & $39,1 \%$ & $73,9 \%$ & $52.7 \%$ \\
At school & $22,8 \%$ & $1,1 \%$ & $3.3 \%$ \\
Other & $3,3 \%$ & $3,8 \%$ & $7.1 \%$ \\
\hline
\end{tabular}

Student participants provided that at home they mostly use desktop, laptop, and desktop computers more than at school and other places. Laptop use at home was observed to be the most common answer provided (73.9\%), and this was followed by tablet use at home $(52.7 \%)$. Because of the mobility of the tablet computers, students stated that they use tablet computer at other places $(7.1 \%)$ than home and school (table 3 ).

Table 4. Years Of Computer Use ( $n=186)$

\begin{tabular}{lccc}
\hline & Desktop & Laptop & Tablet \\
\hline None & $33,7 \%$ & $21,7 \%$ & $37,5 \%$ \\
Less than 1 year & $7,1 \%$ & $10,3 \%$ & $14,1 \%$ \\
More than 1 year & $59,2 \%$ & $67,9 \%$ & $48,4 \%$ \\
Mean & 5,53 & 4,24 & 3,37 \\
Std. Dev. & 3,129 & 2,322 & 2,263 \\
Range & $1-16$ & $1-16$ & $1-16$ \\
\hline
\end{tabular}

Table 4 illustrates that a majority of the students have been using desktop, laptop, and tablet computers for more than 1 year. Even though laptops were stated to be the most common used computer type (67,9\%), the mean year of use for desktop computers were observed to be the highest (5,53 years).

Table 5. Feelings Experienced During Computer Use ( $n=186$, hops=2)

\begin{tabular}{lccc} 
& Desktop & Laptop & Tablet \\
\hline None & $35.9 \%$ & $21.2 \%$ & $37.5 \%$ \\
Frustration & $8.2 \%$ & $6.0 \%$ & $4.3 \%$ \\
Excitement & $18.5 \%$ & $21.2 \%$ & $25.0 \%$ \\
Amazement & $9.8 \%$ & $7.1 \%$ & $6.5 \%$ \\
Suprise & $7.1 \%$ & $5.4 \%$ & $8.2 \%$ \\
Anger & $10.3 \%$ & $6.5 \%$ & $10.3 \%$ \\
Irritation & $13.6 \%$ & $9.2 \%$ & $4.9 \%$
\end{tabular}




\begin{tabular}{lccc} 
Confusion & $9.2 \%$ & $8.7 \%$ & $6.5 \%$ \\
Nervousness & $7.6 \%$ & $4.9 \%$ & $4.3 \%$ \\
Happiness & $32.6 \%$ & $43.5 \%$ & $38.6 \%$ \\
Other & $11.4 \%$ & $17.4 \%$ & $10.9 \%$ \\
\hline
\end{tabular}

Table 5 shows that happiness during laptop use was the most frequent feeling experienced by the students, which was followed by happiness during tablet use. Moreover, the negative feelings (frustration, anger, irritation, confusion, and nervousness) experienced were comparatively less than those positive feeling. Thus, this finding suggests that the students are technology friendly, and they are mostly comfortable during desktop, laptop, and tablet use.

Table 6. Physical / Sport Activities Involved ( $n=186$, hops=2)

\begin{tabular}{cccccc}
\hline Activity & Response & Activity & Response & Activity & Response \\
\hline Athletics & $13.6 \%$ & Boxing & $4.9 \%$ & Table Tennis & $5.4 \%$ \\
Aerobics & $0.0 \%$ & Dance & $13.6 \%$ & Tennis & $9.8 \%$ \\
Badminton & $7.6 \%$ & Fitness & $10.9 \%$ & Volleyball & $19.0 \%$ \\
Basketball & $23.4 \%$ & Football & $39.7 \%$ & Walking & $38.0 \%$ \\
Horse riding & $3.3 \%$ & Hentball & $6.0 \%$ & Swimming & $21.2 \%$ \\
Biking & $26.1 \%$ & Gymnastics & $4.3 \%$ & Other & $16.8 \%$ \\
Playing Music Instruments & $12.5 \%$ & & & & \\
\hline
\end{tabular}

The physical / sport activities presented in table 6 were selected from the literature which are associated and can result in musculoskeletal discomforts. The most common physical activities and sports provided by the students were observed to be football $(39,7 \%)$, walking (38\%), biking $(26,1 \%)$, basketball $(23,4 \%)$, and swimming $(21,3 \%)$

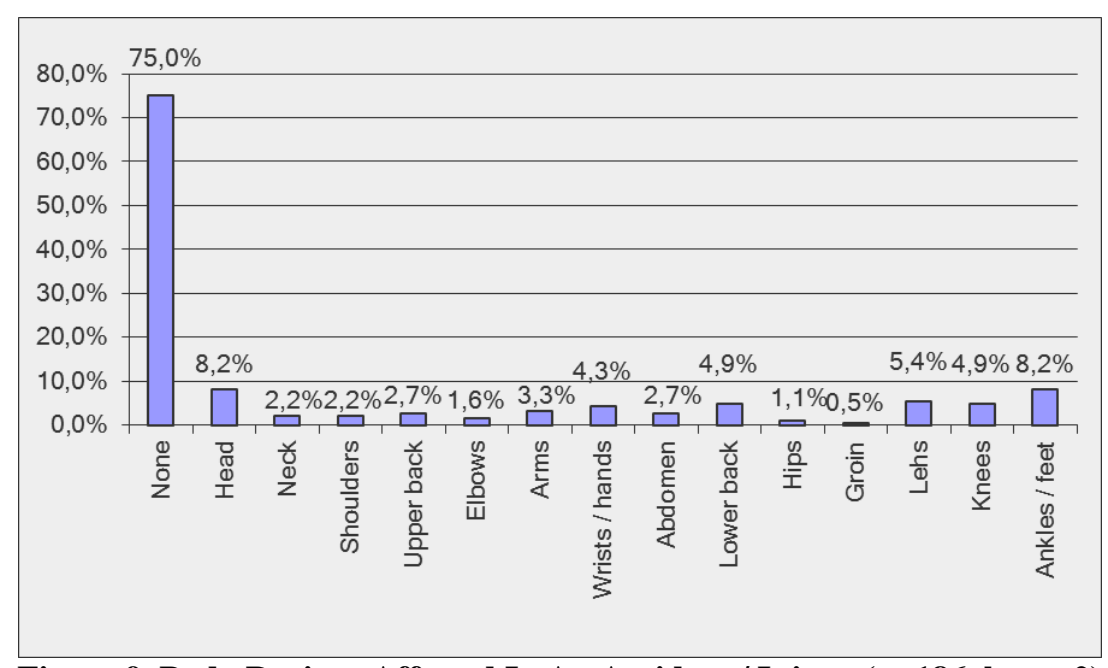

Figure 9. Body Regions Affected In An Accident / Injury (n=186, hops=2)

Musculoskeletal discomforts are not only associated with the physical / sport activities involved, but also accidents or injuries experienced can result in these discomforts. Figure 9 illustrates the body regions affected in an accident or due to an injury. The majority of the students (75\%) stated that they were not involved in an accident or an injury. However, 8,2\% of the students provided that their heads and ankles/feet were affected due to an accident/injury.

Table 7. Use Of Smart Phones For Long Hours During A Normal School Day

\begin{tabular}{|c|c|}
\hline Answer & Response \\
\hline No & $57.6 \%$ \\
\hline Yes & $42.4 \%$ \\
\hline Mean & 3,26 \\
\hline Std. Dev. & 1,837 \\
\hline Range & $1-6$ \\
\hline
\end{tabular}


Likewise computer use, smart phone use involves in repetitive motions, which also contributes to musculoskeletal discomforts. Table 7 shows that $42,4 \%$ of the students use smart phones for long hours in a normal school day, with a mean of 3,26 hours, and standard deviation of 1,837 hours.

Table 8. Experiences Of Ache, Pain, And Discomfort In Body Regions ( $n=186)$

\begin{tabular}{|c|c|c|c|c|c|c|c|c|c|c|c|}
\hline Answer Options & Never & $\begin{array}{c}1-2 \text { times last } \\
\text { week }\end{array}$ & $\begin{array}{c}\text { 3-4 times last } \\
\text { week }\end{array}$ & $\begin{array}{c}\text { Once every } \\
\text { day }\end{array}$ & $\begin{array}{c}\begin{array}{c}\text { Several times } \\
\text { every day }\end{array} \\
\end{array}$ & $\begin{array}{c}\text { Slightly } \\
\text { Uncomfortable }\end{array}$ & $\begin{array}{c}\text { Moderately } \\
\text { Uncomf ortable }\end{array}$ & $\begin{array}{c}\text { Very } \\
\text { Uncomfortable }\end{array}$ & Not at all & $\begin{array}{c}\text { Slightly } \\
\text { Interfered }\end{array}$ & $\begin{array}{c}\text { Substantially } \\
\text { Interfered }\end{array}$ \\
\hline Neck & $48,37 \%$ & $31,52 \%$ & $7,07 \%$ & $2,72 \%$ & $3,26 \%$ & $36,36 \%$ & $16,78 \%$ & $3,50 \%$ & $29,08 \%$ & $24,82 \%$ & $2,84 \%$ \\
\hline Shoulder (Right) & $67,93 \%$ & $11,41 \%$ & $2,72 \%$ & $1,09 \%$ & $4,35 \%$ & $11,89 \%$ & $9,79 \%$ & $4,90 \%$ & $19,15 \%$ & $9,93 \%$ & $1,42 \%$ \\
\hline Shoulder (Left) & $73,37 \%$ & $8,70 \%$ & $2,17 \%$ & $1,63 \%$ & $1,09 \%$ & $9,09 \%$ & $8,39 \%$ & $2,10 \%$ & $17,73 \%$ & $4,26 \%$ & $2,84 \%$ \\
\hline Upper Back & $50,00 \%$ & $18,48 \%$ & $14,13 \%$ & $3,80 \%$ & $4,89 \%$ & $25,87 \%$ & $20,28 \%$ & $6,29 \%$ & $29,08 \%$ & $20,57 \%$ & $3,55 \%$ \\
\hline Upper Arm(Right) & $76,09 \%$ & $8,15 \%$ & $2,72 \%$ & $0,00 \%$ & $0,00 \%$ & $9,79 \%$ & $4,90 \%$ & $1,40 \%$ & $18,44 \%$ & $2,13 \%$ & $0,00 \%$ \\
\hline Upper Arm(Left) & $78,26 \%$ & $6,52 \%$ & $2,72 \%$ & $0,00 \%$ & $0,00 \%$ & $11,89 \%$ & $2,80 \%$ & $1,40 \%$ & $19,86 \%$ & $2,13 \%$ & $0,00 \%$ \\
\hline Lower Back & $48,37 \%$ & $23,37 \%$ & $8,70 \%$ & $2,72 \%$ & $6,52 \%$ & $29,37 \%$ & $16,08 \%$ & $11,19 \%$ & $32,62 \%$ & $17,73 \%$ & $5,67 \%$ \\
\hline Forearm(Right) & $79,35 \%$ & $5,43 \%$ & $0,54 \%$ & $0,54 \%$ & $0,00 \%$ & $6,29 \%$ & $4,90 \%$ & $0,00 \%$ & $15,60 \%$ & $1,42 \%$ & $0,00 \%$ \\
\hline Forearm(Left) & $80,43 \%$ & $3,80 \%$ & $1,09 \%$ & $0,00 \%$ & $0,00 \%$ & $9,09 \%$ & $2,10 \%$ & $0,00 \%$ & $17,02 \%$ & $0,71 \%$ & $0,00 \%$ \\
\hline Wrist (Right) & $66,85 \%$ & $13,04 \%$ & $3,80 \%$ & $0,54 \%$ & $1,63 \%$ & $18,18 \%$ & $6,99 \%$ & $0,70 \%$ & $19,15 \%$ & $7,80 \%$ & $1,42 \%$ \\
\hline Wrist (Left) & $73,37 \%$ & $5,98 \%$ & $3,26 \%$ & $0,54 \%$ & $1,09 \%$ & $11,19 \%$ & $4,90 \%$ & $0,00 \%$ & $17,02 \%$ & $6,38 \%$ & $0,00 \%$ \\
\hline Hands/Fingers (Right) & $73,91 \%$ & $5,98 \%$ & $2,72 \%$ & $1,09 \%$ & $1,09 \%$ & $9,09 \%$ & $4,90 \%$ & $1,40 \%$ & $14,18 \%$ & $4,26 \%$ & $2,13 \%$ \\
\hline Hands/Fingers (Left) & $75,54 \%$ & $5,43 \%$ & $2,72 \%$ & $0,54 \%$ & $2,17 \%$ & $9,79 \%$ & $2,10 \%$ & $1,40 \%$ & $17,73 \%$ & $2,13 \%$ & $2,13 \%$ \\
\hline Hips/Buttocks & $70,65 \%$ & $9,78 \%$ & $2,17 \%$ & $1,63 \%$ & $2,17 \%$ & $13,29 \%$ & $4,90 \%$ & $4,20 \%$ & $19,86 \%$ & $4,26 \%$ & $2,84 \%$ \\
\hline Thigh (Right) & $72,28 \%$ & $9,24 \%$ & $1,63 \%$ & $0,54 \%$ & $1,09 \%$ & $11,19 \%$ & $7,69 \%$ & $0,00 \%$ & $17,73 \%$ & $7,09 \%$ & $0,00 \%$ \\
\hline Thigh (Left) & $73,37 \%$ & $9,24 \%$ & $1,63 \%$ & $0,54 \%$ & $1,09 \%$ & $11,89 \%$ & $5,59 \%$ & $0,00 \%$ & $19,86 \%$ & $4,26 \%$ & $0,00 \%$ \\
\hline Knee (Right) & $76,09 \%$ & $5,43 \%$ & $1,09 \%$ & $2,17 \%$ & $1,63 \%$ & $6,29 \%$ & $7,69 \%$ & $3,50 \%$ & $14,89 \%$ & $7,80 \%$ & $0,71 \%$ \\
\hline Knee (Left) & $75,54 \%$ & $5,98 \%$ & $2,72 \%$ & $2,17 \%$ & $1,09 \%$ & $9,09 \%$ & $5,59 \%$ & $2,10 \%$ & $17,73 \%$ & $5,67 \%$ & $0,71 \%$ \\
\hline Lower Legs (Right) & $73,91 \%$ & $7,61 \%$ & $2,17 \%$ & $1,09 \%$ & $1,09 \%$ & $7,69 \%$ & $6,29 \%$ & $1,40 \%$ & $19,86 \%$ & $2,84 \%$ & $0,71 \%$ \\
\hline Lower Legs (Left) & $72,83 \%$ & $7,61 \%$ & $1,63 \%$ & $1,09 \%$ & $1,09 \%$ & $8,39 \%$ & $6,29 \%$ & $2,10 \%$ & $17,73 \%$ & $4,26 \%$ & $0,71 \%$ \\
\hline
\end{tabular}

Table 8 illustrates the experiences of ache, pain, and discomfort in the specified body regions of the students. It was observed that such discomforts were reported mostly at the neck $(31,52 \%)$, lower back $(23,37 \%)$, and upper back $(18,48 \%)$ 1-2 times during the last week. However, experiencing the ache, pain and discomforts 3-4 times during the last week were observed at the upper back $(14,13 \%)$, lower back $(8,70 \%)$, and neck $(7,07 \%)$, respectively. Once in every day, and several times every day experiences of ache, pain, and discomfort were not significantly reported by the students.

Similar to the above results, $56.64 \%$ of the students reported that their experiences with ache, pain, and discomforts were uncomfortable at the neck and lower back regions, and also 55,44\% provided that these were uncomfortable at the upper back region.

Moreover, $27,66 \%$ of the students stated that they were interfered to study and perform academic activities due to ache, pain, and discomfort experienced at the neck, which was followed by upper back $(24,11 \%)$, and lower back $(23,40 \%)$ problems.

\section{Discriminant Analysis}

Discriminant Analysis was applied to determine whether a set of variables is effective in predicting category membership, and to identify statistically significant factor(s) of the effects of laptop, desktop, and tablet computer use. Therefore, the dependent variable was selected to be the type of computer (desktop, laptop, or tablet) used in daily life of the students. The independent variables were selected from rest of the questionnaire questions (explained in the questionnaire section above).

Table 9. Standardized Canonical Discriminant Function Coefficients

\begin{tabular}{|l|r|r|r|r|r|}
\hline & \multicolumn{5}{|c|}{ Function } \\
\hline & 1 & \multicolumn{1}{|c|}{2} & \multicolumn{1}{c|}{3} & \multicolumn{1}{c|}{4} & \multicolumn{1}{c|}{5} \\
\hline Sch_Des &,- 142 &,- 217 &, 417 &,- 328 &, 812 \\
Locat_Des &,- 397 &,- 311 &, 753 &, 084 &,- 429 \\
Locat_Lap &, 946 &,- 143 &, 400 &,- 128 &,- 113 \\
Locat_Tab &, 001 &, 954 &, 313 &,- 013 &, 009 \\
F_Knee_R &, 425 &,- 047 &, 199 &, 892 &, 301 \\
\hline
\end{tabular}


Table 9 provides the information that desktop computer use at school for lectures, location of desktop computer use, location of laptop use, location of tablet use, and the frequency of experiencing ache, pain, and discomfort in right knee were found to be significant factors (by using SPSS 15).

\section{CONCLUSION}

Computer use is proven to contribute to the formation of musculoskeletal discomfort. With the advances in the technology, computers are more involved in education, with various forms. Desktop computers, laptops, and tablets are actively used for educational purposes. This study was constructed to reveal the ergonomic effects of the computer use for educational purposes on the students $(n=186$, mean age $=14,61)$.

It was challenging to work with students, especially having them to fill out a questionnaire which was made of two sections. In order not to violate the rights of the students, ethic board decision and consent of the students were acquired before the study.

The questionnaire results illustrated that $25 \%$ of the students were using all types of computers (laptop, desktop, and tablet). Even though students were observed to use laptops and tablets more in their daily life, our research showed that desktop computer use, especially at school was one of the significant factors contribute to musculoskeletal discomfort.

The majorities of the students have been using desktop, laptop, and tablet computers for more than 1 year. However, our findings provided that students are experiencing musculoskeletal discomforts highly at the neck, lower back and upper back regions. This finding shows that the students do not recognize the importance of ergonomic posture during computer use.

Not only the experience of ache pain, and discomfort, but also their frequency, especially at the right knee, was found to be significant to the formation of musculoskeletal problems. These discomforts were shown to interfere their studies, and academic activities.

\section{RECOMMENDATIONS}

As the computer use is integrated into education for effective teaching, students should receive ergonomic trainings not to suffer from ergonomic problems, especially musculoskeletal discomforts which may damage their body during the growth phase. This study should be repeated with the contribution of more students to provide generalizability to the study. Thus, the effects of laptop, desktop, and tablet use for educational purposes could be analyzed with a wider population. Routine exercises should be given to the students to develop their musculoskeletal system in order not to suffer from such discomforts.

\section{REFERENCES}

Cornell University Ergonomics Web (CUergo), (1999). Cornell Musculoskeletal Discomfort Questionnaires, http://ergo.human.cornell.edu (Access date: 2014).

Greig, A. M., Straker, L. M., Briggs A. M., (2005). Cervical erector spinae and upper trapezius muscle activity in children using different information technologies, Physiotheraphy, 91, 119-126.

Harris, C., Straker L., (2000). Survey of physical ergonomics issues associated with school children's use of laptop computers, International Journal of Industrial Ergonomics, 26, 337-346.

Hedge, A., Morimoto S., McCrobie D., (1999). Effects of keyboard tray geometry on upper body posture and comfort, Ergonomics, Vol: 42 (10), 1333-1349.

Hildebrandt,V. H., Bongers P. M., van Dijk F. J. H., Kemper H. C. G., Dul J., (2001). Dutch Musculoskeletal Questionnaire: description and basic qualities, Ergonomics, Vol: 44(12), 1038-1055.

Israel, G. D. (2009). Determining a Sample Size, Agricultural Education and Communication Department, Florida Cooperative Extension Service, Institute of Food and Agricultural Sciences, University of Florida. Original publication: November 1992. $\quad$ Reviewed April 2009. http://edis.ifas.ufl.edu/pdffiles/pd/pd00600.pdf

Sommerich, C. M., Ward R., Sikdar K., Payne J., Herman L., (2007). A survey of high school students with ubiquitous access to tablet PCs, Ergonomics, 50(5), 706-727.

Straker, L, Jones K. J., Miller J., (1997). A comparison of the postures assumed when using laptop computers and desktop computers, Applied Ergonomics, 28(4), 263-268.

Straker, L., Coleman J., Skoss R., Maslen B. A., Burgess-Limerick R., Pollock C. M., (2008). A comparison of posture and muscle activity during tablet computer, desktop computer and paper use by young children, Ergonomics, 51(4), 540-555. 